\title{
RESENHA
}

\section{Além do carnaval: \\ A homossexualidade masculina no Brasil no século XX}

Fabrício Romani Gomes ${ }^{1}$

D. Quando a primeira edição de Além do carnaval foi publicada no Brasil, em 1999, eu ainda não tinha iniciado minha formação acadêmica. Mesmo assim, no período de 2001 a 2005, quando estive envolvido com a Licenciatura em História, o livro de

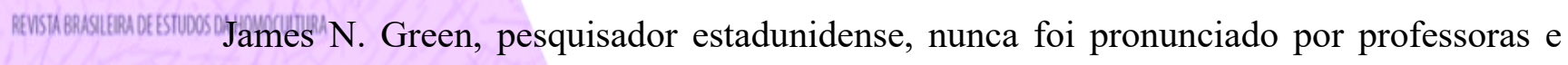
professores, nas mais diversas disciplinas, nem esteve presente nas conversas do Centro Acadêmico de Estudantes. Essa "ausência" pode ter múltiplos sentidos e significados. Um deles se refere ao fato de que o campo da História acadêmica não possui uma tradição consolidada em pesquisas sobre as sexualidades e, em especial, sobre as homossexualidades. Isso vale para o final do século XX, mas também, em certa medida, para o início do XXI. Reflexo disso são as ausências das sexualidades fora da norma nos livros didáticos da área. Neles só há espaço paras a heterossexualidade. Dessa forma, Além do carnaval, obra dividia em seis capítulos, continua, vinte anos depois, sendo importantíssima para a historiografia das sexualidades desviantes em nosso país.

Embora o subtítulo do livro informe que ele trata da homossexualidade masculina no Brasil, durante o século XX, antes de iniciar a análise da pesquisa realizada, Green informa sobre as dificuldades que se apresentaram para a produção de uma investigação de tamanha amplitude. As dimensões geográficas, as diferenças regionais, que implicam nas possibilidades práticas de pesquisa, e o tempo disponível para realização do doutorado são elementos destacados para demonstrar a necessidade de redução da abrangência do estudo.

Dessa forma, o historiador opta pelas capitais do Rio de Janeiro e de São Paulo, decisão que permite o acesso às fontes de forma mais satisfatória. Outra questão que

\footnotetext{
${ }^{1}$ Doutorando no PPG em História da Universidade Federal do Rio Grande do Sul (UFRGS), estudante do curso de "Especialização em Educação: Reflexões e práticas para a Educação Básica", no Instituto Federal do Rio Grande do Sul (IFRS) - Campus Farroupilha. Mestre em História pela Universidade do Vale do Rio dos Sinos (Unisinos) e Licenciado em História pela Universidade de Caxias do Sul (UCS). Professor de História na rede pública de educação básica. Email: fabricio.rgomes79@gmail.com
} 
reduz a amplitude da pesquisa, informada já no título do livro, é o destaque para a homossexualidade masculina. Um dos argumentos utilizados pelo autor para deixar de fora a homossexualidade feminina está relacionado a uma possível invisibilidade das mulheres em fontes por ele utilizadas. Devido a uma situação de vida quase restrita ao ambiente doméstico, as demonstrações públicas da homossexualidade feminina seriam mais raras e dificilmente apareceriam nas páginas de jornais, por exemplo, situação que não acorre com os homens. Isso fica evidenciado já no primeiro capítulo do livro.

Através de charges e do conto $O$ menino do Gouveia, entre outras D (D) possibilidades de fontes impressas, o livro inicia demonstrando aspectos relacionados à D sociabilidade dos homossexuais. Com o título: Os prazeres nos parques do Rio de Janeiro na belle époque brasileira, 1898-1914, o capítulo de abertura demonstra a

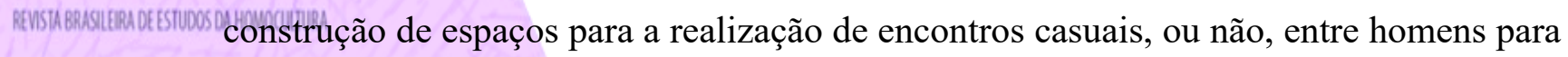
as mais diversas práticas, inclusive as sexuais. Aborda questões relacionadas à prostituição masculina e as visões de diferentes profissionais (médicos e advogados) em relação à homossexualidade.

Como o título do capítulo já informa, a pesquisa fica localizada na cidade do Rio de Janeiro, nesse primeiro momento. Espaços públicos aparecem como os locais preferidos para os encontros. O Largo do Rossio vai ter destaque nesse processo de territorialização das práticas homoeróticas. A disponibilidade para a prática de afetos entre os homens é "camuflada" pelo uso de diferentes símbolos. Green consegue identificar alguns. Sobrancelhas afinadas, uso de maquiagem e lenços de seda pendurados "pareciam constituir um sinal de feminilidade, assim como um código para permitir a aproximação" (GREEN, 2019, p. 96). João do Rio, importante cronista carioca, é um dos personagens que ganha destaque nessas primeiras páginas. As especulações sobre a sua homossexualidade vão ser utilizadas "na tentativa de difamar sua reputação" (GRENN, 2019, p. 111).

A cidade de São Paulo vai aparecer na análise, acompanhada do Rio de Janeiro, a partir do segundo capítulo: Sexo e vida noturna, 1920-1945. Aqui é dada uma atenção maior para as práticas sexuais. A prostituição masculina é um dos temas centrais. A investigação localiza diferentes informações sobre homens que possuem empregos, mais próximos da formalidade, e complementam renda a partir do “comércio" sexual. Em alguns depoimentos deixados por esses homens e encontrados por Green, ele identifica que "muitos homossexuais jovens não apenas aceitavam sua sexualidade, mas de fato a reafirmavam” (p. 134). Parte dessas informações são 
identificadas em relatórios policiais, já que a vigilância sobre essas práticas era intensa. Assim, outros espaços públicos, além das ruas e praças, passam a ser procurados pelos homossexuais. Entre as novas possibilidades para os encontros estão os cinemas e as estações de trem. Outra preocupação do pesquisador é em relação à identificação dos "passivos" e dos "ativos".

Nessa perspectiva, o autor busca confirmar que os homens homossexuais efeminados desempenham um papel "passivo" nas relações sexuais, ou seja, são penetrados. Já os homens "verdadeiros", aqueles que não possuem performances D D efeminadas, seriam os "ativos", aqueles que penetram durante o sexo. Além disso, é Discutida a origem das expressões viado e bicha para fazer referência a esses homens. Ao final do capítulo, Madame Satã surge como uma de suas personagens principais,

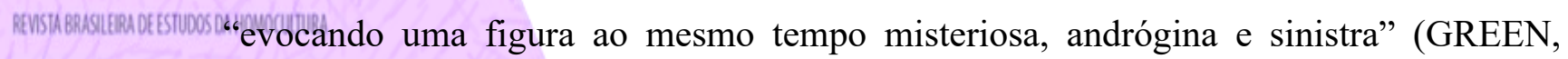
2019. p. 163). Os espaços de presença bicha na cidade se expandem: bares e cabarés na Lapa, ruas e praças em São Paulo. O pânico moral de parte da sociedade é evidente, e Green vai em busca das reações em relação à homossexualidade.

Famílias preocupadas com a vaidade excessiva de alguns dos seus integrantes, o não interesse deles pelo casamento, entre outras supostas evidências para a homossexualidade, fazem pais buscarem ajuda para o "tratamento" dos filhos. Em Controle e cura: reações médico-legais, terceiro capítulo da obra, se confirma que "a polícia, a justiça e a medicina trabalhavam em uníssono para conter e controlar esse 'desvio"” (GREEN, 2019, p. 201). Existiam, segundo esses pensadores da época, possibilidades de amenizar ou afastar de vez a homossexualidade dos homens. Alguns "fatores exógenos, tais como religião e ética, podiam moderá-la ou erradicá-la" (GRENN, 2019, p. 210). Na área judicial, do direito, buscava-se criar um perfil para esses desviantes. As análises chegaram a se aproximar de um protótipo, um modelo corporal que indicaria a homossexualidade da pessoa. Esse viado seria um "homem jovem, de peso abaixo da média, altura mediana e braços e pernas mais compridos que o normal, com um tórax pequeno" (GREEN, 2019, p. 213). Além disso, "mães superprotetoras" (GREEN, 2019, p. 216) eram um perigo, possibilitando o desenvolvimento de filhos homossexuais. Se isso ocorresse, não era preciso entrar em desespero. A "cura" desses homens poderia vir através de uma cirurgia, com o "transplante de testículos" (GREEN, 2019, p. 225). Depois de tantas tentativas, que, em comum, além da perversidade, tinham o insucesso, chegava-se à conclusão de que a homossexualidade era uma "depravação psicológica [que] requeria tratamento médico, e 
não a detenção criminal" (GREEN, 2019, p. 228). A homossexualidade não era caso de política, era caso de saúde! Casas de detenção, quem sabe, já não contassem com tanto espaço. As duas capitais atraíam cada vez mais gente.

Esse crescimento urbano das cidades de São Paulo e do Rio de Janeiro vai contextualizar a abertura do quarto capítulo, Novas palavras, novos espaços, novas identidades, 1945-1968. Crescendo a população, aumenta o número de homossexuais. As duas cidades passam a ser vistas como promessas para uma vida de práticas homoeróticas distante das famílias e das redes de parentesco sanguíneas. Nesses novos D (D) contextos, jovens que passam a viver nesses dois centros urbanos começam a estabelecer contatos e criar "famílias alternativas". Já não é a biologia que define o que são famílias. As redes de amigos estruturam a vida desses homossexuais. Algumas ganham até nome. É o caso da Turma OK. Em grupos maiores, os viados passam a disputar novos territórios. Algumas praias cariocas são o cenário das lutas pelo afastamento de grupos de homossexuais de determinados espaços. Clubes noturnos, escuros e barulhentos se proliferam. A realização dos concursos de Miss Brasil também passa a ser ponto de alta frequência das bichas. Nas bancas, a procura é por revistas que seriam para o público masculino heterossexual, mas, por exibirem nas imagens corpos musculosos de homens, passam a ser consumidas pelos homossexuais. Os novos arranjos de solidariedade fazem surgir alguns jornais específicos: $O$ Snob ganha destaque. Entre os exemplares publicados, Green encontrou Os Dez Mandamentos da Bicha. Entre eles, estavam: "1 - Amar todos os homens; [...]; 6 - Fingir que ama um só; [...]; 10 - Casar só por uma hora" (GREEN, 2019, p. 315). Novas identidades se formam. E o carnaval é o melhor período para amar todos os homens!

Entendido como uma festa de inversão, o carnaval é o tempo para esses homens colocarem a peruca, o vestido ou a minissaia, usarem um batom vermelho e irem aproveitar a festa. É nesse sentido que ocorre $A$ apropriação homossexual do carnaval carioca, tratada no capítulo cinco. Além da participação nos blocos e nas festas de carnaval de rua, os homossexuais encontram outras possibilidades de participação. É no carnaval que as efeminadas podem exagerar nos trejeitos sem a preocupação com os vigilantes. No cordão do Bola Preta, em 1941, foi escolhida a "Rainha Moma" (GREEN, 2019, p. 350). Os bailes para escolha de rainhas são bastante frequentados pelos viados. Além deles, começam a ser frequentes os bailes das travestis, os concursos de fantasia, o Baile das Bonecas, o Baile dos Enxutos, expressão que passou a ser utilizada para fazer referência aos homens homossexuais (GREEN, 2019, 
p. 370). Todo esse ambiente festivo é divulgado nacional e internacionalmente e "reforça a imagem do Brasil como um paraíso para os renegados sexuais e transgressores dos papéis de gênero convencionais" (GREEN, 2019, p. 341). Nesse cenário, em que as escolas de samba do Rio de Janeiro estão em plena consolidação, como uma das maiores belezas do carnaval brasileiro, Joãosinho Trinta e Clóvis Bornay são alguns dos homossexuais que passam a se "apropriar" desses espaços. O clima festivo trazido pelo capítulo vai sendo alterado pelas transformações políticas dos anos 1960.

D. Na última parte da pesquisa, Green vai analisar a homossexualidade masculina N 1 durante o período ditatorial brasileiro. Em “Abaixo a repressão: mais amor e mais tesão", 1969-1980, as fontes trabalhadas pelo historiador nos demonstram a prática do

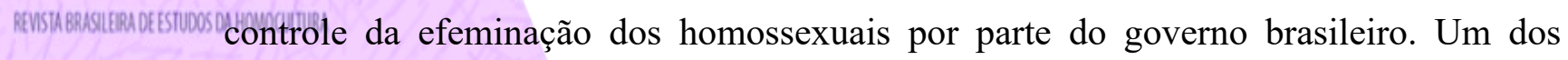
casos mencionados ocorre em 1972, quando "o Conselho de Censura e Juizado de Menores de Belo Horizonte exigiu que dois estilistas de moda fossem banidos da televisão" (GREEN, 2019, p. 409). Nesse período, também é identificado pelo autor o aumento do número de travestis nas ruas. E, embora exista uma repressão contra a efeminação em períodos fora do carnaval, nesse contexto, surgem figuras andróginas através do grupo teatral Dzi Croquettes e das performances de Ney Matogrosso, muitas das quais chegaram até as famílias brasileiras por um dos programas mais tradicionais da televisão nacional, o Fantástico. Além disso, nesse período, começa a circular por meio de diferentes publicações expressões como "Gay Power" (GREEN, 2019, p. 427). Entre os impressos veiculados especificamente para a população homossexual ganham destaque os jornais Gente Gay, Mundo Gay e Lampião da Esquina. Esse último, em especial, circula nacionalmente e possibilita uma percepção mais ampla sobre as experiências homossexuais pelo Brasil, motivando, inclusive, a identificação de problemas comuns. O encerramento do capítulo se dá no momento de surgimento do primeiro grupo do movimento homossexual no país, que posteriormente vai de chamar de Somos.

A publicação da segunda edição dessa importante obra, em 2019, pode auxiliar na consolidação de diversos projetos, na área da História, que estão sendo desenvolvidos pelo Brasil e buscam incentivar a pesquisa das sexualidades e dos gêneros nesse campo. Um exemplo é o projeto Close, que pretende ser um centro de referência da História Lgbtqi+ do Rio Grande do Sul. Além disso, Além do carnaval faz uma reflexão importante sobre as liberdades dadas aos homossexuais no período das 
festas carnavalescas, o que cria a aparência de que vivemos em um país que respeita as diversidades, em contraste com a repressão e violência ocorrida no restante dos dias, situação que leva o Brasil ao topo no número de assassinatos de LGBTs no mundo. Por fim, fica a torcida para que, quem sabe, nosso carnaval possa não ter fim!

\section{Referências}

GREEN, James N. Além do carnaval: a homossexualidade masculina no Brasil do século XX. Tradução: Cristina Fino e Cássio Arantes Leite. 2. ed. São Paulo: Editora nCD 대에 2019. 